\title{
A percepção do espectador sobre o movimento do corpo que dança
}

\author{
Perception of the Spectator \\ on the Movement of the Body that Dances
}

\section{La percepción del espectador sobre el movimiento del cuerpo que danza}

Rubiane Falkenberg Zancan*

http://dx.doi.org/10.22409/poiesis.1932.21-36

\begin{abstract}
RESUMO: Este texto apresenta aspectos da apreciação em dança e composições coreográficas com ênfase no próprio movimento. Busca-se evidenciar especificidades da dança que envolvem a apreciação e a composição. O texto proporciona pensar sobre a valorização do conhecimento sensível pela via da apreciação em dança. São ressaltadas as especificidades das experiências em dança marcadas pela presença, isto é, pelo encontro no espaço e tempo que produz no espectador sensações corporais, como vibrações, arrepios e vontade de mover-se. Além disso, a percepção ampliada e o estado alterado de vigília durante o processo de recepção em dança são destacados.
\end{abstract}

PALAVRAS-CHAVE: dança; recepção; percepção; composição; sensibilidade

\footnotetext{
" Rubiane Falkenberg Zancan é doutoranda em Artes Cênicas da Universidade Federal do Rio Grande do Sul (UFRGS), mestre em Artes Cênicas pela UFRGS e docente do Curso de Licenciatura em Dança da Universidade Federal do Rio Grande do Sul (UFRGS). E-mail: rubianezancan@hotmail.com
} 
ABSTRACT: This text presents aspects related to the appreciation in dance and choreographic compositions with emphasis on the movement itself. Thus, it aims to evidence the dance specificities that involve appreciation and composition. This text allows us to think about the appreciation of sensitive knowledge through the appreciation in dance. It emphasizes the dance experiences specificities marked by the presence, that is to say, by the encounter in the space and time that produces in the spectator corporal sensations, such as vibrations, shivers, and will to move. Furthermore, the enhanced perception and altered state of wakefulness during the dance reception process are highlighted.

KEYWORDS: dance; reception; perception; composition; sensitivity

RESUMEN: Este texto presenta aspectos de la apreciación en danza y composiciones coreográficas con énfasis en el propio movimiento. Se busca evidenciar especificidades de la danza que implican la apreciación y la composición. El texto proporciona pensar sobre la valorización del conocimiento sensible por la vía de la apreciación en danza. Se resaltan las especificidades de las experiencias en danza marcadas por la presencia, es decir, por el encuentro en el espacio y tiempo que produce en el espectador sensaciones corporales, como vibraciones, escalofríos y voluntad de moverse. Además, se destacan la percepción ampliada y el estado alterado de vigilia durante el proceso de recepción en danza.

PALABRAS CLAVE: danza; recepción; percepción; composición; sensibilidad

Como citar: ZANCAN, Rubiane Falkenberg. A percepção do espectador sobre o movimento do corpo que dança. Poiésis, Niterói, v. 19, n. 32, p. 21-36, jul./dez. 2018.

doi: http://dx.doi.org/10.22409/poiesis.1932.21-36

Poiésis, Niterói, v. 19, n. 32, jul./dez. 2018. 


\section{A percepção do espectador sobre o movimento do corpo que dança}

\section{Introdução}

Este texto procura enfatizar as criações em dança que têm como mote principal o movimento e sua relação com o conhecimento sensível no processo de recepção estética do ponto de vista do espectador. Pretendo ressaltar o tipo de composição coreográfica que está atenta ao movimento, e não à ideia que a apresentação poderá comunicar algo específico ao espectador. Desse modo, busco tratar sobre o que interage na recepção estética por meio da expressão do movimento, defendendo a valorização do conhecimento sensível.

\section{Sobre a criação em dança pautada no movimento}

O corpo estabelece sua comunicação pelo modo que agencia sua relação com a gravidade, com a força que emprega na movimentação, com o percurso que traça no espaço, com o tempo que executa; ou seja, o movimento corporal em seus micro e macro ajustes produz informações. A dança trabalha fundamentalmente com o movimento corporal. É importante salientar que a coreografia pode apresentar uma narrativa, contar uma história. Entretanto, o recorte deste texto está pautado na possibilidade de fazer dança sobre o próprio movimento. 
Segundo Eliana Rodrigues Silva (2005), ao referir-se aos trabalhos do coreógrafo Merce Cunningham da década de 1960 nos Estados Unidos, as qualidades estruturais da dança eram motivos suficientes para a criação coreográfica que, por sua vez, transformou-se naquele momento em uma moldura, uma janela por onde olhar o movimento em si mesmo.

Algumas composições, como as de Cunningham, partem do estímulo cinestésico e por isso não têm o compromisso de comunicar nada além de sua própria natureza. Desse modo, ao entender aqui o conceito da palavra natureza como aquilo que tem relação com suas características, os subsídios que constituem aspectos estruturais da dança operam com as motivações que envolvem sua criação. As combinações de movimentos, a priori, se estabelecem sem a necessidade de definir uma denominação. No momento da recepção estética, essa criação ganha vida na percepção do espectador, que sente e que pode atribuir sentidos.

De acordo com Smith-Autard (2000), quando a coreografia está pautada especificamente na exploração das possibilidades do movimento, não se pretende transmitir uma ideia pré-concebida, mas um estilo, uma atmosfera, um campo de dinâmicas, padrões e formas. Para a autora, esses aspectos do movimento, ou da frase de movimento, podem ser usados e desenvolvidos para criar uma composição coreográfica baseada na exposição do movimento em si.

Apresento esses parágrafos iniciais com a argumentação de que a dança pode ser sobre o próprio movimento e, dessa forma, para problematizar se há a necessidade de entendermos o que a dança quis dizer. Será que esse tipo de composição de dança pretende estabelecer o mesmo tipo de operação presente no raciocínio lógico? O que a composição coreográfica pautada no próprio movimento pode provocar no espectador? Michel Bernard afirma que o espectador de dança,

contrariamente aquele de todas as outras artes da cena, [...] não dispõe da grade de inteligibilidade fornecida pela hegemonia do trabalho já significante do texto e da situação dramática e deve, por consequência, elaborar seu próprio modelo de leitura, escolhendo suas próprias normas de conexão perceptiva. (BERNARD, 2001, p. 210)

Poiésis, Niterói, v. 19, n. 32, jul./dez. 2018. 
Já que o espectador geralmente está condicionado a buscar um sentido para aquilo que assiste, é provável que se sinta mais confortável quando, em alguma medida, encontra nos espetáculos de dança a teatralização. Esse aspecto se demonstra em algumas composições coreográficas pelo uso da expressão fônica, da construção narrativa, das mímicas expressivas. Entretanto, quando a composição em dança é sobre o movimento surge outro modo de relacionar-se com aquilo que assiste.

Ao analisar a percepção de um objeto artístico singular como a dança, Bernard (2001) busca destacar a especificidade da realização ou da exploração dessa função pela dança, isto é, a originalidade do espetáculo coreográfico relativamente aos outros espetáculos. Assim, ele menciona quatro características pelas quais define as peculiaridades da dança como arte, a saber:

- sua dinâmica de metamorfose indefinida, a embriaguez de movimento por sua própria mudança;

- seu jogo aleatório e paradoxal de "tecer" e "destecer" da temporalidade: a corporeidade dançante não cessa de se dissolver e de se reconstituir na sucessão de seus instantes, no fluxo imatrizável de uma duração que ela tenta tornar visivel como aparência única e visivel. "0 instante, escreve Valéry, engendra a forma e a forma faz o instante";

- seu desafio obstinado à gravitação terrestre ou, se preferirem, seu diálogo incessante e conflitado com o peso pela alternância dos apoios e impulsos.

- enfim, sua pulsão autoafetiva ou autorreflexiva, quer dizer, o desejo constitutivo de todo o processo expressivo, no senso etimológico da palavra, do retorno da corporeidade e sobre ela mesma, desejo que encontra sua matriz nos processos vocais, no qual toda manifestação visível não é senão a sombra carregada de sua dinâmica invisível. Assim, a dança não faz senão exibir e orquestrar esta vocalidade virtual, esta musicalidade fantasmagórica e carnal da nossa corporeidade. (BERNARD, 2001, p. 209)

Os quatro traços específicos da dança definidos por Bernard (2001) indicam o modo de recepção do espectador, na medida em que ele se depara com movimentos produzidos pelos corpos dos bailarinos. A movimentação realizada pelos bailarinos incita o espectador a acompanhar as várias incursões dos corpos no espaço. O corpo, por meio de movimentos, apresenta configurações que se organizam espaço-temporalmente e produzem infor- 
mações que chegam pelos sentidos: são percebidas, selecionadas, organizadas e interpretadas. Cada espectador faz diferentes seleções do que vê e, consequentemente, tem diferentes resultados receptivos.

Bernard (2001) ressalta que existe "[...] uma diferença essencial da recepção que singulariza sempre a dança: aquela das condições e das modalidades de leitura e escrita coreográfica, enquanto ligação ambígua dos códigos da corporeidade dançante com os sentidos." (BERNARD, 2001, p. 210).

Uma das condições e modalidades de leitura possíveis, pela ambiguidade presente nos códigos do corpo dançante e da produção de sentido, seria entender o processo receptivo como um campo de promessas. Desse modo, os traços comunicativos apresentados pela coreografia, que não possuem uma codificação com decifração exata, são entendidos como uma indicação de algo que exerce ação sobre a imaginação do espectador. Essa modalidade de leitura é diferente daquela que ocorre, por exemplo, na comunicação verbal, em que o processo é marcado pelo ciclo constituído de uma mensagem emitida que é decifrada por meio de simbolizações codificadas para que haja um entendimento o mais próximo possível.

Duarte Junior (2000) lembra que nosso conhecimento ocorre pela via dos sentimentos e da simbolização: "A linguagem fornece o sistema simbólico básico para que o homem se volte sobre suas experiências e as compreenda, atribuindo-Ihe significações". (DUARTE JUNIOR, 2000, p. 74) Assim, compreendo que a percepção está em constante negociação com aquilo que se sente e suas vias de simbolização. Pela percepção estamos constantemente produzindo sentido. Existe, portanto, na condição humana, um modo de operar que articula sentimento e simbolização: "A percepção que temos do mundo é construída pela linguagem, que fragmenta e ordena aquele modo de perceber primitivo, sincrético (ou global)". (DUARTE JUNIOR, 2000, p. 74)

Muitas vezes, quando o espectador assiste à dança, a ênfase presente na apreensão recai sobre o sentimento. A noção de sentimento é entendida aqui no mesmo sentido que Du-

Poiésis, Niterói, v. 19, n. 32, jul./dez. 2018. 
arte Junior (2000) argumenta, relacionado à forma primitiva do conhecimento humano, como a impressão primeira: "Portanto, neste caso, tem-se a consideração do sentimento como uma percepção global, direta, da situação que nos encontramos". Dessa forma, o autor enfatiza a noção de que o sentimento é "uma maneira emotiva de relacionamento com o mundo". (DUARTE JUNIOR, 2000, p. 74)

Trazendo essa noção para o campo da dança, a potência gerada pelo corpo em movimento afeta principalmente a ordem dos sentimentos, daquilo que ainda não foi conceitualizado pela linguagem. Inclusive, muitas vezes, faltam símbolos para sistematizar aquilo que assisti por meio da linguagem. Por isso, nesses casos, o espectador pode sentir um desamparo frente à recepção em dança. Retomando a abordagem de Duarte Junior, " nessa percepção primeira, o mundo não é visto como algo neutro, mas como um campo de promessas e ameaças". (DUARTE JUNIOR, 2000, p. 74)

Michel Bernard (2001) indaga sobre o processo complexo que envolve a percepção na dança ao questionar: " quais são as modalidades especificas da percepção de corpos dançantes em um local cênico e em um momento determinado?" (BERNARD, 2001, p. 205) Observo nesta pergunta que o autor aponta dois aspectos da presença: o espaço e o tempo. O espectador de dança tem sua experiência marcada pela presença, na medida em que a materialidade da dança dissolve-se e desaparece no espaço e no tempo. É uma experiência ligada com encontro daquele corpo que dança e daquele corpo que assiste.

Para reforçar essa problematização, Bernard (2001) argumenta ainda que o espectador de dança se depara com corpos em mobilidade permanente, com as aparições fugazes, múltiplas e imprevisíveis. Para ele, essas características "não permitem ao espectador profano, contrariamente a todas as formas de espetáculo, circunscrever, fixar, retificar, identificar, compreender e interpretar imediatamente o conteúdo percebido." (BERNARD, 2001, p. 205)

Qual quer que seja o prazer espontaneamente experimentado no instante, o espectador se sente um pouco desamparado e não sabe qual atitude perceptiva adotar, quer dizer, como dispor, guiar seu olhar e sua escuta relativamente à estranheza das aparências furtivas que se impõe a ele. (BERNARD, 2001, p. 205) 
Como a dança é marcada pela experiência da presença, algumas vezes o espectador retém mais a primeira impressão, aquela mais primitiva relacionada aos sentimentos. 0 tempo de assimilação das formas complexas apresentadas pelos corpos que dançam, por não ter códigos explícitos presentes na linguagem, pode dificultar a simbolização imediata. Ao ter a experiência do todo, isto é, ao sairmos do espetáculo, a produção de sentido continua ativa.

No caso das composições coreográficas sobre o próprio movimento, às vezes o espectador não tem outra escolha senão acompanhar os rastros deixados pelo corpo dançante. $O$ espectador frente a um espetáculo predominantemente composto pelo movimento corporal se vê levado a seguir algo que insiste em ficar retido pelos sentimentos, pelas sensações e emoções. A força está em sua impressão primeira, no sentimento produzido pela afetação que temos sobre aquilo que assistimos.

Para destacar o movimento como a matéria prima da dança, trago um trecho escrito por Hubert Godard (2002) sobre a análise da coreografia solo de Trisha Brown, denominada If You Couldn't See Me, de 1994.

Integral mente dançado de costas, esse solo é a quintessência de dezenas de anos de trabalho. [.. . . nessa obra não se vê praticamente nenhum signo afirmativo: braços e pernas não se fixam em forma e parecem apenas prolongamento de tensões que trabal ham com o espaço original, no nível da emergência do prémovimento, precisamente lá onde se joga o equilíbrio postural. 0 público não tem outra saída a não ser ver a "tela de fundo", o lugar de origem do movimento [...]. Trisha Brown esconde também os signos produzidos pela face, sendo o rosto um dos raros lugares do corpo onde se inscreve uma retórica imediatamente legível. Escondendo seu rosto, ela priva o público de signos de afeto, proíbe qualquer interpretação intempestiva de sua dança [...]. (GODARD, 2002, p. 28)

Destaco que, nessas danças constituídas pela combinação de movimentos e que tratam do movimento, não existe uma preocupação do artista em gerar uma produção de sentido de algo que possa ser decifrado pelos códigos da linguagem falada e escrita. Uma das alternativas para o espectador é mergulhar no mundo do movimento. Neste caso, o espectador pode dançar junto ao sentir o movimento em seu corpo.

Poiésis, Niterói, v. 19, n. 32, jul./dez. 2018. 
Duarte Junior (2000), ao tecer suas considerações sobre sentimento-compreensão, ressalta o quanto é difícil explicar por meio de palavras a separação entre esses dois domínios na nossa vida cotidiana, "já que o pensamento procura sempre lançar sua rede conceitual aos oceanos de nossas mais intimas sensações, procurando envolvê-las e explicálas discursivamente". (DUARTE JUNIOR, 2000, p. 75) No entanto, ele pondera: "Há um domínio íntimo aonde a linguagem não pode chegar, que permanece inacessível aos conceitos verbais". (DUARTE JUNIOR, 2000, p. 75) A partir desta concepção, entendo que em uma parte de sua experiência apreciativa, o espectador de dança é tocado pelo domínio íntimo inacessível pela conceitualização.

Sabemos que estamos o tempo todo produzindo sentidos, mas o que quero destacar é que podemos aceitar estar nessa dimensão na qual a força está em não conceituar. Apresento esta sugestão como um convite para um tipo de experiência mais voltada à sensibilidade humana.

\section{As impressões dos espectadores sobre o movimento}

Com o intuito de apresentar algumas experiências sensíveis presentes na recepção de dança e pensar sua relação com as modalidades de leituras e o movimento do corpo dançante, trago alguns trechos de depoimentos de espectadores gravados após assistir espetáculos. Essas falas foram produzidas para meu estudo de doutorado ${ }^{1}$. A pesquisa coletou essas informações para identificar as atividades dos espectadores de dança. Para tanto, o participante voluntário: a) respondeu ao questionário sobre seu perfil; b) assistiu espetáculos de danças selecionados pelos editais de ocupação dos Teatros Municipais de Porto Alegre, Rio Grande do Sul; c) gravou depoimentos sobre seu processo de recepção imediatamente após sair do espetáculo, sem contato com outra pessoa.

Com essa proposta de abordar o tema pelo viés do que denomino de recepção aplicada, tive a oportunidade de trabalhar com informações profundas, com um número relativamente pequeno de pessoas, o que resulta em uma compreensão de suas experiências sobre os espetáculos de dança de um contexto específico, mas que pode ser pensado em uma visão macro. 
O público deste estudo foi composto de vinte e quatro acadêmicos do Curso de Licenciatura em Dança da Universidade Federal do Rio Grande do Sul, que aceitaram participar da pesquisa. Eles assistiram a oito apresentações de dança de diferentes tipos (dança contemporânea, dança do ventre, dança tribal, folclore brasileiro de projeção, dança aérea, danças urbanas) durante o segundo semestre de 2016. As citações que seguem, com nomes fictícios que iniciam com a letra " $E^{2}{ }^{2}$, são oriundas dessas informações coletadas.

Na pesquisa de doutorado, abordo as atividades dos espectadores de dança por meio de três categorias: dimensão criativa, dimensão sensível e dimensão conceitual. Para este texto, escolhi apresentar as impressões relativas ao movimento pelo ponto de vista do espectador e destacar alguns trechos que trazem as impressões com as quais os espectadores se referem aos aspectos dos movimentos da dança em que há a predominância da dimensão sensível. Desse modo, busco identificar rastros daquilo que pode estar próximo da impressão primeira, mais primitiva. Entretanto, sabemos que a elaboração do discurso, sobre o que foi assistido, carrega a mediação e a conceitualização presente na linguagem.

\section{O espectador e o movimento do corpo que dança}

Cada vez mais, os sentimentos têm sido negligenciados, desvalorizados, quando pensamos no campo do conhecer. No entanto, sabemos que o conhecimento humano ocorre pela conexão entre sentimento e compreensão, como via de mão dupla de afetamentos. Com isso, consideramos que os modos de sentir e simbolizar fazem parte da produção do conhecimento humano, embora exista uma desvalorização do conhecimento sensível. Duarte Junior (2000) relata que " é ainda interessante notar-se que as ciências humanas, com algumas exceções, têm-se descuidado da esfera do sentir enquanto forma básica do conhecimento humano". (DUARTE JUNIOR, 2000, p. 76) Cada vez mais, existe uma valorização daquilo que pode ser quantificável. "Como as emoções não são objetos, como sentimentos não podem ser quantificáveis, por exprimir fundamentalmente uma maneira de ser em relação mundo, emoções e sentimentos deixaram de ser significativos". (DUARTE JUNIOR, 2000, p. 76)

Poiésis, Niterói, v. 19, n. 32, jul./dez. 2018. 
Tanto em seu fazer quanto em seu apreciar, a dança é uma arte que tem sua potência marcada pelo modo como atinge o corpo humano com suas emoções e seus sentimentos. Por meio da dança, entramos em contato com os saberes corporais. Por isso, este texto destaca os aspectos que envolvem a ordem do conhecimento sensível, o que não quer dizer que a dança não trabalhe com a simbolização, com a compreensão e com o conhecimento que pode ser quantificado. Entretanto, a escolha aqui é valorizar a sensibilidade como forma de conhecimento e mostrar como ela está presente na recepção em dança.

Ressalto, neste texto, a relação entre a percepção que o espectador tem sobre o movimento. Para tanto, inicio trazendo alguns depoimentos de espectadores que descrevem seus interesses pelo modo que o corpo se move em cena:

[... ] 0 corpo inteiro fazendo 0 esforço para fazer o movimento, e elas tinham uma questão muito interessante que é, umas apoiavam as outras. As que estavam em cima do tecido eram apoiadas pelas que estavam no chão. À medida que elas trocavam de posição, porque as que estavam abaixo logo iam subir, elas mantinham uma simetria no movimento que me chamou a atenção. (EVA, 2016)

A atenção da espectadora se volta para a técnica corporal apresentada. Seu olhar está atento aos detalhes da movimentação. Como também é abordado pela espectadora Érica: "Quando eu assisto dança do ventre eu fico hipnotizada pelo abdômen, eu fico olhando, e aham... [sic] eu pareço um zumbi olhando para barriga das pessoas se mexendo... aham... [sic] perguntando como que aquilo mexe...". Mais adiante em seu depoimento, ela completa: "era legal perceber a diferença de cada abdômen, de cada barriga e o desenho, e volume, eu fico meio viajando nisso, eu fico aaaahhh [sic], abdômen... sério! Isso acontece." (ÉRICA, 2016).

Muitas vezes, o espectador é capturado pelo movimento e busca acompanhar as formações espaciais, a velocidade, o percurso, a iniciação do movimento e seu sequenciamento. Uma espectadora diz: "me chamou a atenção, tinha sete rampas, sete rampas no palco." (EVA, 2016) e, a partir do impacto visual, descreve sua percepção: 
[... ] eles faziam um deslocamento sempre com a mesma sequência, todo o espetáculo foi com a mesma sequência de deslocamento, e eles iam mudando o nível, subindo e descendo a rampa, ou então, sempre mudava as posições e o deslocamento era sempre o mesmo e em determinado momento eles formavam uma roda, repetiam a mesma sequência de passos na roda e faziam um jogo de palmas; ficou bonito, gostei dessa parte, achei muito criativo. (EVA, 2016)

O modo como o corpo do bailarino se move e os deslocamentos coreográficos que eles fazem no palco são destacados pelas formas visuais criadas ao percorrer o espaço. Percebo, nesses depoimentos iniciais, um modo de dizer marcado pela descrição. Os espectadores contam o que assistiram, o que chamou sua atenção, mas não procuram trazer uma interpretação, no sentido da representação, isto é, como algo que está no lugar de outro. Os espectadores acompanham e observam os movimentos cênicos como material explorado pela dança.

A criação sensível é destacada pela espectadora Érica. Ela descreve aspectos da criação poética que instigam sua percepção: "[...] quando as varas descem com as luzes incandescentes, as lâmpadas incandescentes, aquilo é tão importante, aquilo dá um fechamento, diminui o espaço, aham ( $\mathrm{sic}$ ), fecha de uma forma tão bonita, toda a discussão em torno da luz". (ÉRICA, 2016) Neste depoimento, podemos observar a valorização perceptiva em relação à motivação visual produzida pela composição coreográfica.

Eloisa liberta-se da busca pela decifração de códigos e diz: "[...] eu não entendi nada, mas foi pra mim, acho que foi o jogo das luzes, a música, eu consegui viver aquilo, sabe? Eu consegui ser afetada, sabe?" Ela lida com a experiência permitindo-se estar nessa ordem mais direta de apreensão das coisas do mundo, ao dizer: "Eu consegui sentir. Isso eu achei legal [...], fui afetada por isso, foi quase que vivi o movimento, vivi a sensação que a coreógrafa quis passar". (ELOÍSA, 2016) No momento e no tempo do espetáculo de dança, no encontro entre o público e a coreografia, ocorre à mobilização de sensações que se manifestam no corpo de quem assiste.

Podemos observar a sensibilização impulsionada pelo movimento produzido pela dança no depoimento de Eugênia: "Eu senti muito arrepio nas minhas costas e nas minhas pernas,

Poiésis, Niterói, v. 19, n. 32, jul./dez. 2018. 
tinha tipo uma vibração, que eu não sei, a música também. Eu sentia como se ela, tudo fizesse vibrar em mim, e o corpo tivesse pulsando e vibrando". (EUGÊNIA, 2016) A percepção do espetáculo é corporal, é sentida no corpo por meio de vibração, calor, sudorese, arrepios, vontade de movimentar-se. Além de toda a sensação física descrita, também é salientada a relação com a sonoridade, que pode ser considerada uma reação de empatia cinestésica. Segundo Reason e Reynolds (2010), "as experiências auditivas de dança podem ser conceituadas em termos de respostas ao movimento, mais proeminentemente em termos do que foi descrito como empatia cinestésica". (REASON; REYNOLDS, 2010, p. 49) Eloísa também nos conta sobre suas sensações: "Em princípio, vertigem, eu senti vertigem, não sei se foi por causa dos movimentos repetitivos dos bailarinos no começo e pela trilha sonora que também era muito repetitiva". (ELOÍSA, 2016) Podemos observar a atividade corporal sendo exercida no processo receptivo pela sensação de vertigem. Os movimentos implicados na constituição poética de uma dança articulam-se com a percepção do espectador. O movimento é o que existe de palpável, real, concreto que extrapola para o campo de apreensão sensível.

A relação entre o movimento produzido pela dança e sua percepção pelo espectador já foi defendida no início do século XX pelo teórico John Martin. De acordo com Foster (2011), John Martin defendeu uma relação vital entre o dançarino e o espectador a partir da conexão entre o movimento e a emoção. Embora sentados em seus lugares, disse ele, os espectadores sentem os movimentos e, consequentemente, as emoções dos dançarinos. Atualmente existem estudos no campo da neurociência que aprofundam esse tema.

Essa conexão entre movimento e emoção é evidenciada na fala de Elaine, que diz: "[...] é... achei que a iluminação foi muito bem utilizada no espetáculo... e ele me deu vontade de dançar [risos]... deu vontade de dançar, de... suar [risos]". (ELAINE, 2016) O espectador é atingido pelo movimento do corpo dançante, fazendo emergir sensações em seu próprio corpo. Como podemos ver, a recepção em dança tem forte ação corporal, exerce efeito no corpo de quem assiste. Além disso, pode levar o espectador a sentir uma sensação de percepção ampliada, por exemplo, dos sentidos visuais, auditivos e cinestésicos. 
Eugênia relata que o espetáculo a deixou em um estado muito meditativo. Ela explica: "Eu sinto que eu fiquei nesse olhar, eu me senti com um olhar fixo assim, olhando pra tudo, e vendo tudo, mas ao mesmo tempo sem pensar muito. Em muitos momentos eu senti isso acontecer. E agora eu tô meio nada. Sei lá, eu sai meio zonza da sala". (EUGÊNIA, 2016) Neste depoimento, podemos perceber que há um estado alterado de vigília. Além disso, os aspectos relativos ao modo de atuação de sua capacidade sensorial revelam um estado de percepção ampliada.

Quando um espetáculo de dança consegue nos tocar por meio de uma percepção ampliada é porque houve uma alteração da sensação dos sentidos. No nosso dia a dia, raramente focamos em nossa percepção do mundo; ao contrário, priorizamos o raciocínio lógico. A experiência estética é uma possibilidade de mudar essa lógica de funcionamento e de afetar nossas sensações.

\section{Considerações Finais}

Dependendo do modo como o espetáculo trabalha em nós, ou seja, quando ele consegue proporcionar um exercício em que atinge fortemente nossas emoções e sensações, embarcamos nesse território que nos distancia da razão, do modo de operar racional. A percepção desse estado que escapa do controle nos coloca em uma dimensão diferente daquela que encontra uma resposta, uma interpretação pela via da produção de sentidos. Deste modo, nos permite experienciar um estar ali, naquele tempo, com aquelas sensações.

Perceber esses momentos raros e vivenciá-los é, portanto, uma forma de mergulhar em outra consciência. A maioria das pessoas se assusta com essa percepção, ou mesmo não a percebe, e logo busca um meio de quebrar isso, transformando a sensação em palavras.

A recepção em dança pode estar marcada pela percepção ampliada e pela alteração do nosso modo de sentir-se naquele tempo e espaço. Nesses casos, o espectador explora a atividade sensível, mas também é tocado pela criação de ideias. Mesmo sem nos afas-

Poiésis, Niterói, v. 19, n. 32, jul./dez. 2018. 
tarmos totalmente do nosso senso de realidade, em alguns raros momentos, entramos em uma troca de intensidades que nos permitem perder a razão, o bom senso e o pensamento lógico presentes no cotidiano. Essa razão é justificada pelo tipo de material predominantemente utilizado na criação da dança, o corpo em movimento. O processo receptivo em dança pode, sem nos tirar da cadeira, fazer com que nos movimentemos juntos com os bailarinos. Às vezes, podemos sentir o movimento incessante, ora em direção ao fluxo de energia produzida pela dança, ora em direção à alteração do nosso estado corporal. O movimento desse jogo ocorre por aproximações e não por decifração.

\section{Notas}

\footnotetext{
1 As informações sobre recepção estética na dança abordadas neste texto fazem parte do tema que estou estudando desde a dissertação de mestrado, concluído em 2009, e, agora, também na tese de doutorado em andamento. A dissertação intitulada Motivação Criadora e Recepção Estética no Espetáculo Re-Sintos da Muovere Companhia de Dança foi orientada pelo Professor Clóvis Dias Massa. A pesquisa analisou como acontece a articulação entre dança e teatro no espetáculo Re-Sintos da Muovere Companhia de Dança de Porto Alegre, verificou o que envolve o processo de recepção e como o espetáculo se oferece ao exercício receptivo e, por fim, examinou e apresentou o modo como opera a produção e a recepção do espetáculo Re-Sintos a partir de algumas características aproximativas do rizoma de Gilles Deleuze e Félix Guatarri. Já no doutorado em andamento, identifico as atividades dos espectadores de dança durante o processo de recepção de espetáculos de diferentes tipos de dança. A tese, intitulada $O$ Espectador na Dança: um estudo de recepção aplicada, está sendo orientada pelo Professor Doutor Walter Lima Torres Neto. Tanto o mestrado quanto o doutorado foram realizados no Programa de PósGraduação em Artes Cênicas da Universidade Federal do Rio Grande do Sul. Ambas as pesquisas são fontes deste artigo.

${ }^{2}$ As referências dos depoimentos dos espectadores voluntários citados neste texto, com nomes fictícios iniciados com a letra "E", fazem parte do material produzido no período de 31 de agosto a 18 de dezembro de 2016 para a tese de doutorado em andamento intitulada O Espectador na Dança: um estudo de recepção aplicada.
} 


\section{Referências}

BERNARD, Michel. De la création choregrafique. Tradução livre de Helena Maria Mello. Paris: Centre National de La Danse, 2001.

DUARTE JUNIOR, João Francisco. Fundamentos estéticos da educação. Campinas: Papirus, 2000.

FOSTER, Susan Leigh. Choreographing Empathy: Kinesthesia in Performance. Tradução livre de Natália Ferreira. Nova York: Routledge, 2011.

GODARD, Hubert. Gesto e percepção. In: SOTER, Silvia; PEREIRA, Roberto (Org.) Lições de dança. Rio de Janeiro: UniverCidade, 2002, p. 11-35.

REASON, Matthew; REYNOLDS, Dee. Kinesthesia, Empathy, and Related Pleasures: An Inquiry into Audience Experiences of Watching Dance. Dance Research Journal, [S.I.], v. 42, n. 2, p. 49-75, 2010. Disponível em https://www.cambridge.org/core/journals/dance-research-journal/article/kinesthesia-empathy-and-related-pleasures-an-inquiry-intoaudience-experiences-of-watching-dance/. Acesso em 20/4/2018.

SMITH-AUTARD, Jaqueline. Dance Composition. Tradução livre de Cibele Sastre. Londres: Routledge USA by arregement with A \& C Black Publishers Limeted, 2000.

SILVA, Eliana Rodrigues. Dança e pós-modernidade. Salvador: EDUFBA, 2005. 